NASA TID-D $366 C$

NASA Technical Memorandum 83666

\title{
A Review of Internal Combustion Engine Combustion Chamber Process Studies at NASA Lewis Research Center
}

Harold J. Schock

Lewis Research Center

Cleveland, Ohio

Prepared for the

Twentieth Joint Propulsion Conference

cosponsored by the AIAA, SAE, and ASME

Cincinnati, Ohio, June 11-13, 1984 


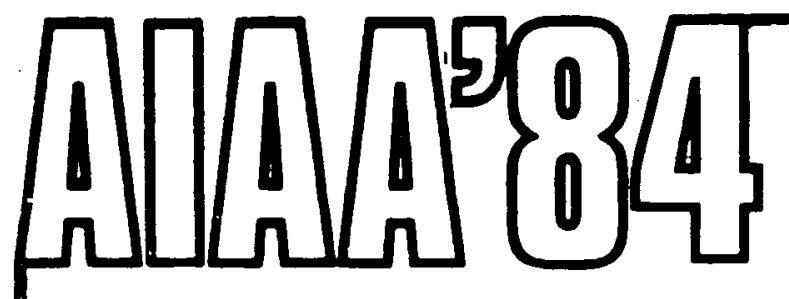

AIAA-84-1316

A Review of Internal Combustion Engine

Combustion Chamber Process Studies at

NASA Lewis Research Center

Harold J. Schock, NASA Lewis Research

Center, Cleveland, $\mathrm{OH}$

\section{AIAA/SAE/ASME \\ 20th Joint Propulsion Conference \\ June 11-13, 1984/Cincinnati, Ohio}




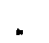

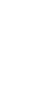




\title{
A REVIEW OF INTERNAL COMBUSTION ENGINE COMBUSTION
}

\section{CHAMBER PROCESS STUDIES AT NASA LEWIS RESEARCH CENTER}

\author{
Harold J. Schock* \\ National Aeronautics and Space Administration \\ Lewis Research Center \\ Cleveland, Ohio 44135
}

\section{Abstract}

This paper describes work underway at NASA Lewis Research Center whose objective is to determine the in-cylinder airflow characteristics of rotary and piston engines. Experience has shown that performance of internal combustion stratified-charge engines is highly dependent on the in-cylinder fuel-air mixing processes occurring in these engines. Results showing the output of multi-dimensional models, laser velocimetry measurements and the application of a unique holographic optical element are described. Models which simulate the four-stroke cycle and seal dynamics of rotary engines are also described.

\section{Introduction}

Internal combustion (I.C.) engine optimization has been underway for well over 100 years. It has not been until the last 10 years that tools have been available to perform the in-situ studies necessary to gain a fundamental understanding of the processes occurring in the engines of interest. Two devices which have reached the level of refinement necessary to study the processes which occur during combustion in these engines are the laser and the high-speed digital computer.

Understanding the fundamental details of airflow and fuel pyrolysis in an internal combustion engine will lead to the development of engines with high efficiency, long life, and good power-to-weight ratio characteristics. Designs which are optimized for manufacturing economy can also be considered, once suitable predictive codes have been developed. This paper describes the research effort underway in the Intermittent Combustion Engine Branch at NASA Lewis Research Center for understanding the com- bustion processes occurring in these engines.

\section{Background}

The following brief discussion is intended to give those who are not involved in this activity a feeling for the current status of incylinder I.C. engine research. This is also given to set the stage for a description of the Intermittent Combustion Engine Branch's basic research effort and a description of the philosophy upon which this effort is based.

I.C. engine in-cylinder process studies can be categorized as experimental or as a numerical simulation, and the analysis can be either macroscopic or microscopic. Equally important but not included in this type of classification

\footnotetext{
* Aerospace Engineer
}

are numerical studies or experiments which are system-related. This type of study is not discussed in this report, but it would include engine/turbocharger or engine system/plane/flight analysis studies.

The macroscopic predictions include thermodynamic or quasi-dimensional models. These models attempt to simulate the processes occurring in the combustion chamber of an engine without modeling the actual physical details of each process. Thermodynamic models can vary a great deal in complexity. They can be highly idealized process models, which include assumptions such as constant volume heat addition, reversible compression and expansion, and zero heat losses or complex cycle analyses which have been refined over many years. An example of the latter is given by the MIT group 1 where it has used experimental pressure-crank angle histories to deduce the rate at which fuel is burned in a lightly loaded stratified-charge engine. The object of that particular study was to analyze the causes of hydrocarbon emission mechanisms in directly injected spark-ignition engines. Every major center of engine research has codes of this type operational, and most have been reported at SAE during the last three years.

The usefulness of the thermodynamic models just described depends heavily on the availability of high quality pressure data, valve flow coefficients, heat transfer data, macroscopic air flow rates and other data such as air/fuel ratios, etc. The development of high speed digital electronic devices has made it possible to measure indicated mean effective pressure on a real-time basis. ${ }^{2}$ This allows one to examine cycle-to-cycle variability, as well as enginedependent intake and exhaust manifold characteristics.

Microscopic analysis, in theory, offers the potential of understanding the details of the combustion process in engines of interest. The physical processes of importance are air motion, turbulence level, fuel mixing and evaporation, combustion, and heat transfer. The boundary conditions at the intake and exhaust valves are of particular importance to the simulation and are particularly difficult to determine. The engine flows of interest are three-dimensional in nature, and a fine grid system is required to resolve the flow details of importance. A threedimensional simulation of the four-stroke cycle would include submodels such as a turbulence model, detailed fuel spray and mixing models, multi-step kinetics, and a grid size small enough to resolve the important flow details near the surfaces. A coded model of this type would require a computational time on the order of 100 CPU hours, even on the fastest available machine today such as a CRAY I. 
At this time, not enough information is known about the accuracy of each submodel to warrant assembling a code of this magnitude. The complex interaction of fuel sprays with surrounding air and the mode of vaporization and oxidation of multi-dimensional spray in a steady environment is not well understood at this time. The detailed modeling of the combustion of fuel sprays in a highly unsteady engine environment is even more complicated.

The full-flow field models just discussed offer the potential of gaining a fundamental understanding of processes which occur in an internal combustion engine. At this point, predictive codes are not in good agreement with measured results. The development of these codes will depend on very careful experiments for comparison with predicted results. A further discussion on the present status of flow field modeling is deferred until the end of this section. Experimental techniques used for local in-cylinder analysis and model verification are now briefly discussed.

One of the most important microscopic measurements in use at the present time is Laser Doppler Velocimetry (LDV). Laser velocimetry allows one to make non-intrusive velocity measurements in the combustion chamber of an operating engine. The ability to make cycle resolved velocity measurements requires configuration of LOV systems which will provide high data counting rates and also computer systems which would provide high data transfer rates. Other nonintrusive, and generally laser-based techniques, allow for measurement of local temperatures, fuel/aircombustion produçt compositions, burning rates, and flame speed. $3,4,5$ A first step for understanding these processes is the ability to perform flow visualizations. As early as 1872 Nicholas 0tto built a glass cylinder engine ${ }^{6}$ which was hand cranked; however, most flow visualizations in piston engines have relied on the use of flat windows to study flame propagation and combustion. In the early $1940^{\prime} \mathrm{s}$, an important flow visualization study of knock was reported by $C$. D. Miller ${ }^{7}$, using a rotating prism camera which he designed. This camera was capable of framing rates to 200,000 frames per second. Present day cameras based on the Miller principle allow one to make photographs at framing rates greater than 2.5 million frames per second ${ }^{8}$. Miller believes that this framing rate would be sufficient to observe the salient features of knock in an I.C. engine. 9 Geometrical considerations have impeded flow visualization studies in firing piston engines. Recently Richman 10 reported on the development of a transparent cylinder engine for fluid mechanics research. He demonstrated that holographic optical elements can be used as an aberration corrector in a piston-cyl inder, schlieren flow visualization system. The schijieren technique produces spatial averaged density gradient information. For complicated flows such as those that occur within an engine, this type of information is difficult to interpret and compare with model predictions.

Most groups working on engine research have recognized the importance of full-flow field models, and numerous researchers have published the results of their work. A fairly complete list of these publications can be found in the reference section of a report by Shih. 11

The multi-dimensional modeling effort underway at the Imperial College has been the most extensive one to date. Recently, they presented the results of a three-dimensional airflow simulation using a $\mathrm{K}-\mathrm{E}$ turbulence model to close the ensemble averaged conservation equations. 12

The Imperial college group has also made extensive single component velocity measurements in their motored axisymmetric piston-cylinder configuratjon to verify the results of their models.13 For low speed operation (200 RPM), qualitative agreement between mean velocities predicted by the model and the experiments has been shown. Inlet geometry and combustion chamber dimensions are the factors which influence vortical structure formation during the early part of the intake stroke. 13,14 For the axisymmetric piston-cylinder configuration, the exact nature of the dependence of the vortical structures formed during intake on the initial and boundary conditions has not been well documented. Further, the nature of the vortical structure break-up during compression has not been verified and is not well understood. To the author's knowledge, not a single flow visualization of the airflow pattern in an axisymmetric piston-cylinder configuration has ever been published.

\section{Intermittent Combustion Engine Branch Basic Research Effort}

The in-cylinder process studies underway in the Intermittent Combustion Engine Branch is based on an analysis approach which combines numerical simulations with detailed experimental studies. In general, since numerical simulations $c$ an be developed on nearly any computational machine, and are readily transported from one location to another, these efforts have been conducted via grants. The success of an experimental build-up required for combustion chamber process studies in our experience is very sensitive to personnel changes. Also, the experimental apparatus generally requires several parttime support people. The Intermittent Combustion Engine Branch has chosen to perform this type of work at NASA Lewis Research Center, with some exceptions.

Although not discussed in this report, the Intermittent Combustion Engine Branch is also supporting stress analysis studies for rotary and piston engines, high temperature material studies, fuel injection and engine controls work. Many of these efforts will produce important engine design information during the present year.

The above studies briefly mentioned, and the in-cylinder process studies about to be described, are designed to give a good understanding of the factors which influence the weight, performance, and reliability of the engines of interest. These studies are designed in such a way that information from one experiment or simulation is used as initial or boundary conditions for another. The ultimate goal of this work is the development of a new class of light aircraft 

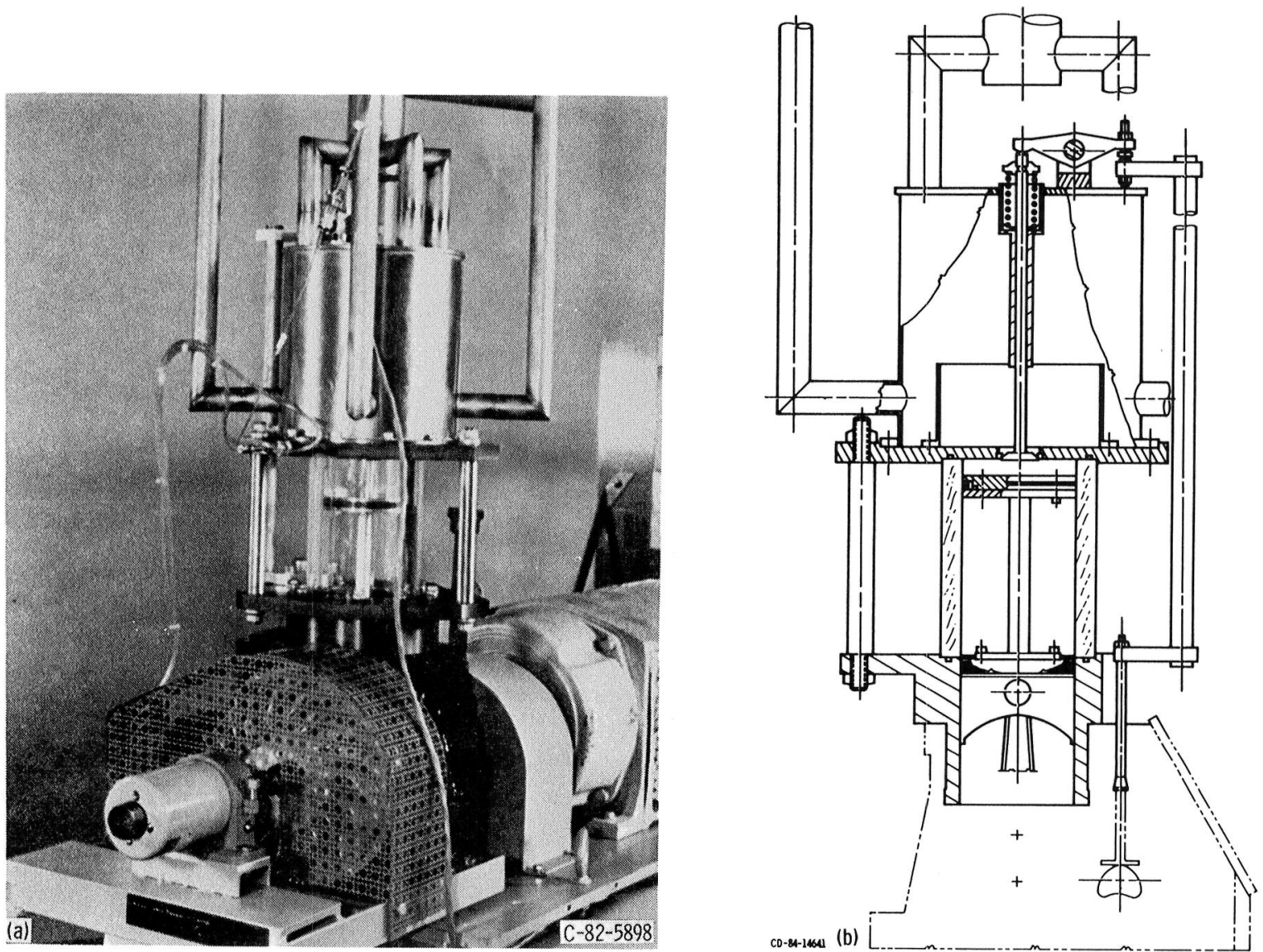

Figure 1. - (a) Photograph of axisymmetric piston-cylinder configuration. (b) Schematic of axisymmetric piston-cylinder configuration.

engines capable of delivering $1.5 \mathrm{HP} / \mathrm{lb}(0.5$ $\mathrm{kw} / \mathrm{kg}$ ) with a brake specific fuel consumption of $0.30 \mathrm{lbm} / \mathrm{HP}-\mathrm{hr}(182 \mathrm{~g} / \mathrm{kw} \mathrm{hr})$.

The details of the cylinder process research studies are now given.

Laser velocimetry studies. In order to understand how fuel and air are burned in an internal combustion engine, it is first necessary to be able to understand the air motion. For flow studies in a piston-cylinder configuration such as shown in Figure 1, except for the clearance volume region, a nonintrusive technique is almost mandatory for measurement of these flows. LDV is the ideal tool to make point measurements in this configuration. Figure 2 shows a photograph of the LDV engine system now operational at Lewis Research Center. 15

The model engine used in this experiment was specifically designed to provide an axisymmetric flow inside the cylinder. A standard four-stroke single-cylinder engine was retrofitted with a second piston and cylinder. The upper stage piston was bolted directly to the lower stage piston. The upper cylinder was seated into a groove which was machined into the lower cylinder. A special cylinder head was constructed to

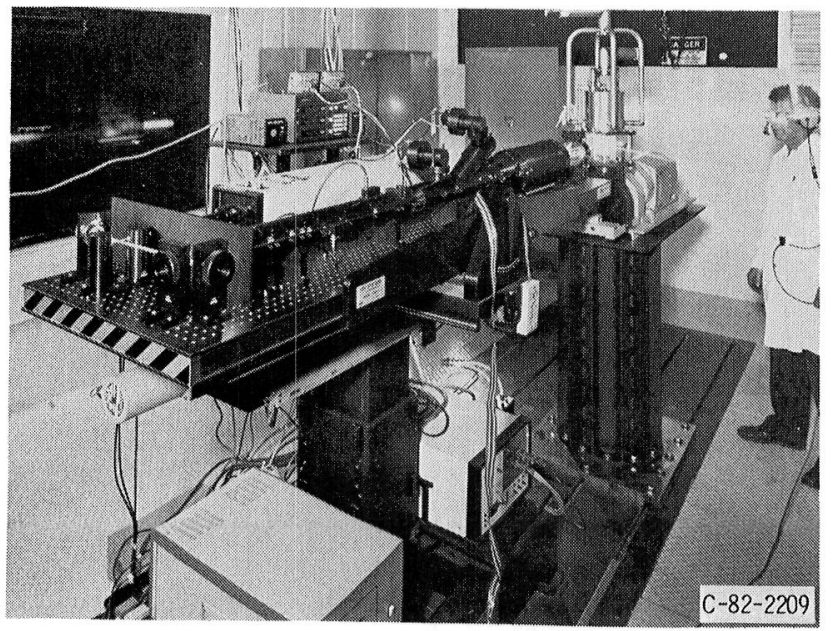

Figure 2. - Photograph of LDV system at LeRC.

replace the standard two-valve configuration, so that a single valve could be located at the center of the head. This special cylinder head incorporated a large manifold, so that incoming 

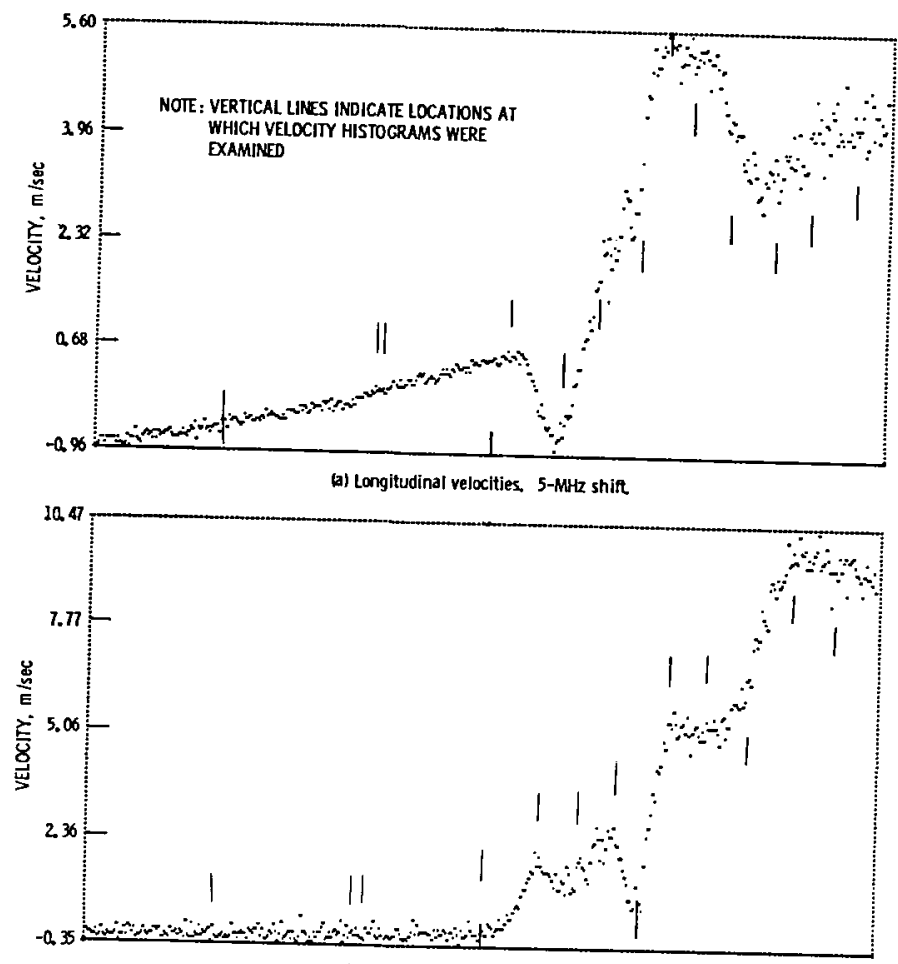

(b) Radial velocities. 2-MHz shift.

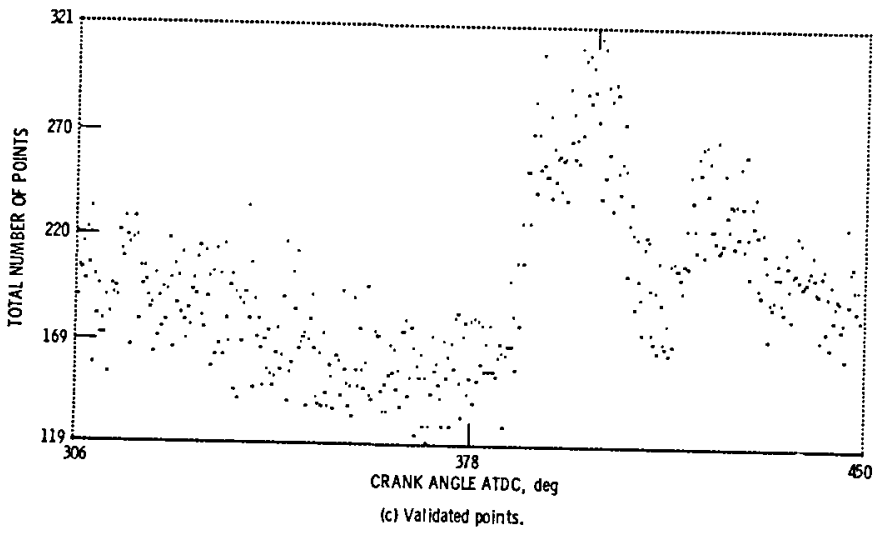

Figure 3. - Typical velocity measurements taken with DV system. 
and exhaust air could be kept as near to ambient pressure as possible. The manifold had a series of tubes connected to the top and bottom of it. Seeding particles were introduced into the bottom set of tubes and flowed around a baffle before being swept into the cylinder. Outgoing exhaust air exited through the top of the manifold. The model engine was fitted with a pressure transducer located near the center line of the head, and a 10-bit rotary shaft angle encoder was connected to the crankshaft. The four-stroke cycle was divided into 2048 windows using first or second revolution information and an optical shaft angle encoder with a $0.352^{\circ}$ resolution. Under its present configuration, the engine can be motored from speeds of approximately 300 RPM to 1500 RPM.

The upper cylinder was constructed of quartz and was polished to a surface finish of $40 / 20$ scratch dig as per mil spec MIL-0-13830A. The refractive index of the quartz cylinder was 1.46 and the wall thickness was 0.36 inches. This relatively thin wall cylinder provided adequate signals, as long as the interior surface could be kept clean.

Historically, LDV velocity measurements have been restricted to either one or two components of velocity. Measuring the third component, i.e., on-axis, has been the most difficult, particularly in an internal combustion engine where accessibility is limited. An optical system that uses a patented technique 16 employing three coplanar beams to measure the radial velocity was used for this set of experiments. Longitudinal and azimuthal velocities can also be measured using the same optical system.

This optical system is a commercially available three-component configuration. The light source is a four-watt Argon-Ion laser incorporating a temperature controlled etalon. The laser is operated in the multiline mode in order to create both a blue (488nm) and green (514.5nm) line. A dispersion prism separates these lines and a set of mirrors is used to steer the beams into the optical train. Modular optics are used to derive a five-beam configuration exiting from the focusing lens. Two of the exiting beams are blue and correspond to a standard single component LDV system (azimuthal component). The other three beams are green and are used to obtain both the longitudinal and radial velocity components. Thus, all three orthogonal velocity components $c$ an be simultaneously measured at a point, using the five-beam arrangement.

An example of the output of this system is shown in Figure 3 . A sample size was selected to be 100,000 crank angle/velocity pairs. The counters were set in coincidence mode. This allowed the software to process the data either by individual components, or by analyzing the vector created by the discrete component measurements. The sample size of 100,000 data points typically took four to five minutes to collect and one hour to process using a DEC PDP 11/23.

Holographic optical systems for laser velocimetry. Recent work has shown that multifaceted holographic optical elements can be used to correct aberrations introduced into the optical system of a Laser Doppler Velocimeter by a nonflat window. For this experiment, three green beams, each separated by $41.25 \mathrm{~mm}$ in the vertical plane, and two blue beams separated by $82.50 \mathrm{~mm}$ in a horizontal plane are brought into coincident focus inside a plexiglass cylinder (Figure 4). The focal power to bring these beams to a common focus and the aberration correction required by the presence of the cylinder were built into the holographic elements. The principle demonstrated using the elements described is applicable for an arbitrary window geometry.
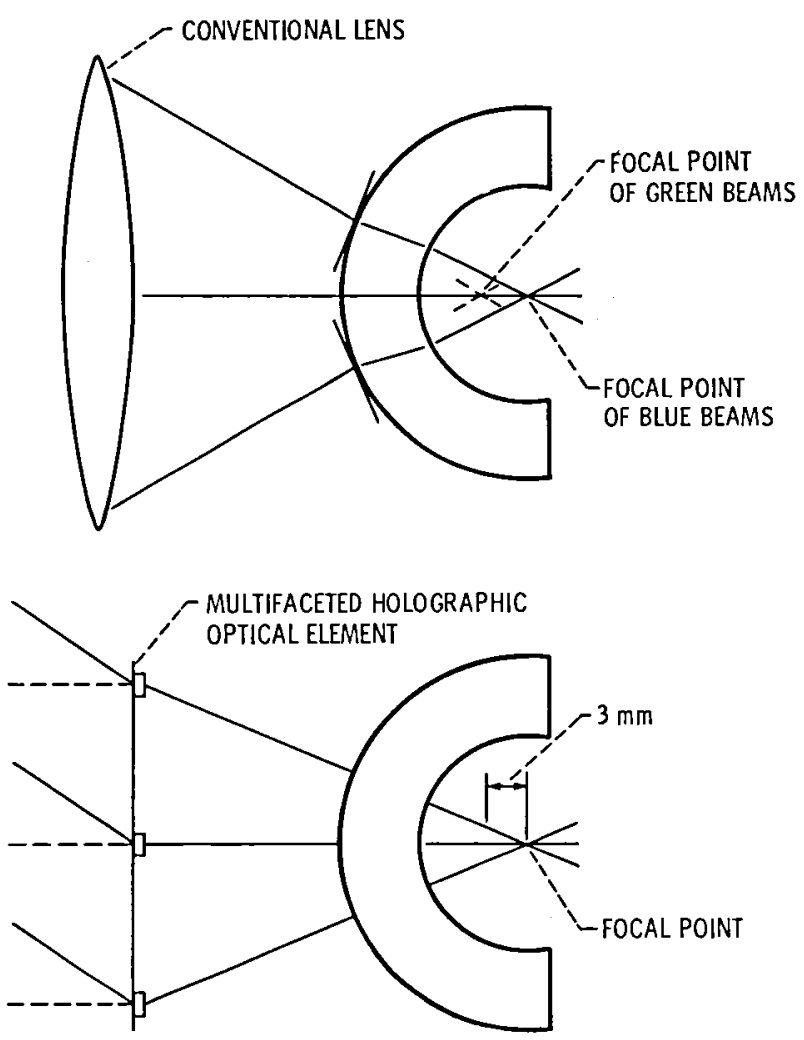

Figure 4. - Laser beams inside a plexiglas cylinder with and without corrective element.

Figure 5 shows the intersection of the blue and green beams near the cylinder wall using a conventional lens. It is noted that the blue and green beams do not come to a common focal point at the same location within the cylinder.

Figure 6 shows the same beams being brought into coincident focus using a mult if aceted holographic optical element. As each beam requires its own correction, depending upon the location at which it was brought into the cylinder, this technique is the only one known to this author which will perform the desired correction. This will allow for the measurement of quantities such as Reynolds stresses, which were previously not attainable for all locations within a cylinder.

Figure 7 is a photograph of the interference fringes formed inside a five-eighth inch thick sapphire cylinder using the holographic technique described. This technique is suitable to any container geometry and the elements can also be used as collecting optics to color separate, and focus the output Doppler signal onto the aperture of a photodetector. 

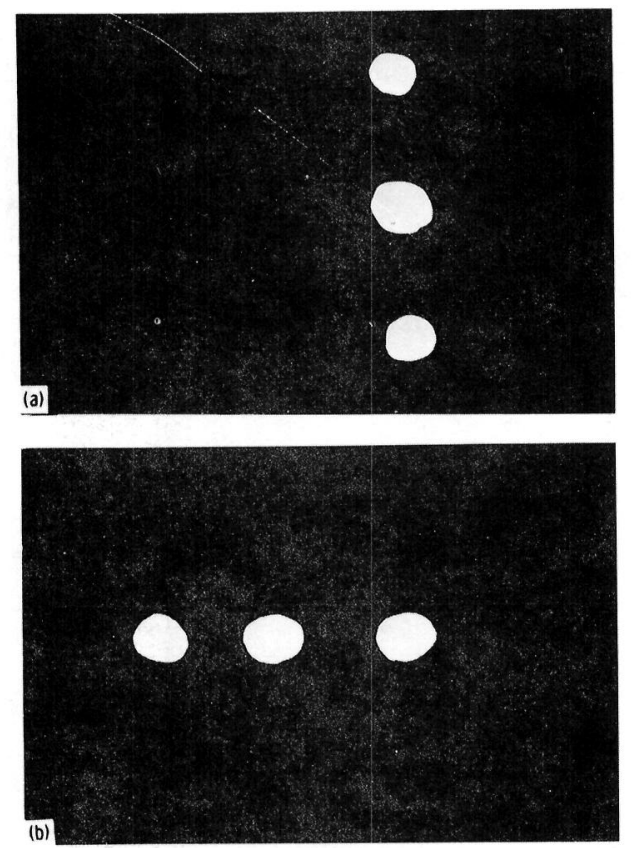

Figure 5. - (a) Plane in which the blue beams over lap (center spot) $1 \mathrm{~cm}$ from the inner wall of the cylinder. (b) Plane in which the green beams overlap $\mathrm{lcm}$ from the inner wall of the cylinder.
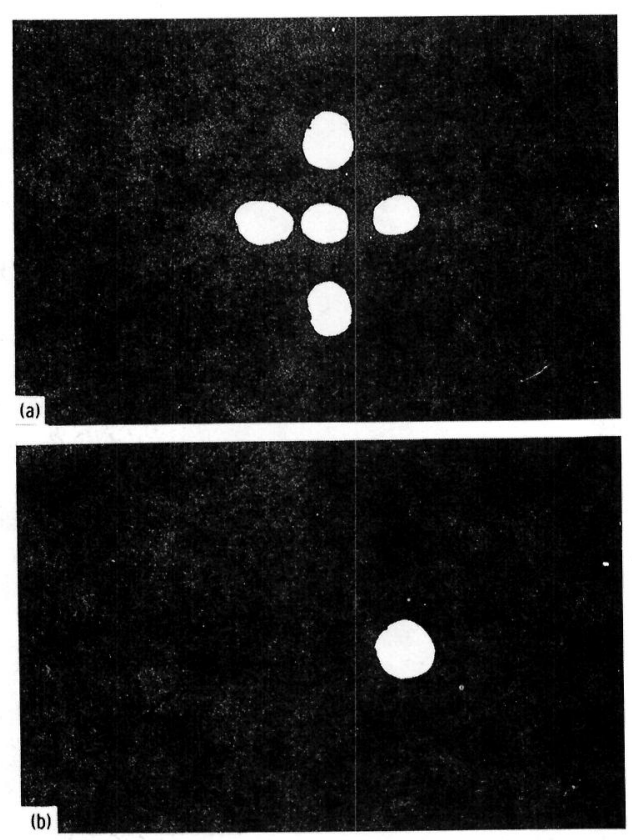

Figure 6. - (a) Five beams inside the cylinder, $1 \mathrm{~cm}$ from the cylinder wall at a distance $z=3.2 \mathrm{~mm}$ from the focal point (10x expansion). (b) Five beams inside the cylinder, $1 \mathrm{~cm}$ from the cylinder wall at the focal point (10x expansion).

Rotary combustion engine seal dynamics. Seal leakage and high seal friction have been cited as factors causing poor fuel economy in the rotary combustion engine (RCE). In order to examine rotary seal dynamics, a cooperative effort between researchers at Michigan Technological University and the Intermittent Combustion Engine
Branch at Lewis Research Center was initiated and the initial phase completed. The results of this study included the development of a code which predicts RCE seal dynamics. 18

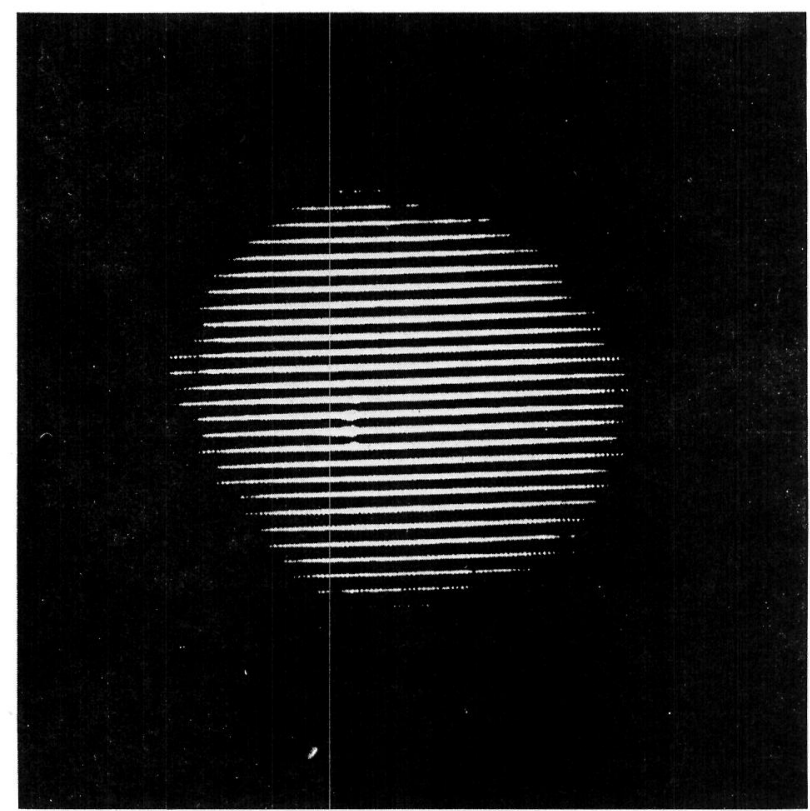

Figure 7. - Interference fringes formed inside a 5/8 in. thick sapphire cylinder using holographic lens.

Real-time work cell pressures are incorporated into a dynamic analysis of the gas sealing grid in a rotary combustion engine. The analysis, which utilizes only first principle concepts, accounts for apex seal separation between the sides of its restraining channel and apex seal rotation within the restraining channel. The results predict that apex seals do separate from the trochoidal bore, and shift between the sides of their channels. They also show that these two motions are regularly initiated by a seal rotation. The predicted motion of the apex seals is similar to the experimental results. Frictional losses associated with the sealing grid are also calculated and compare well with measurements obtained in a similar engine. A comparison of frictional losses for various sealing configurations was made. This comparison included steel versus carbon apex seals as well as friction losses for single and dual side sealing.

Normalized gas sealing mean effective pressure (GSMEP) friction losses are shown for the apex seals and side seals in Figure 8 . The most interesting aspect of this study showed that the friction losses due to the side seals are of the same order of magnitude and possibly larger than apex seal frictional losses.

The next step is to combine this simulation with the thermodynamic model to produce a more realistic picture of the effects of RCE seal leakage and friction.

Study of jet ignition using liquid fuels. High temperature fuel jet combustion studies have 
been underway at the University of California Berkeley, over the past three years. 19 The prime motivation of this work is to determine under what conditions preheating of the fuel offers a significant combustion rate controlling mechanism not now available. If ignition delay can be controlled by preheating a fuel, engines could operate at very high efficiencies regardless of the quality of the fuel.

\section{FIRING 100 PERCENT THROTTLE}

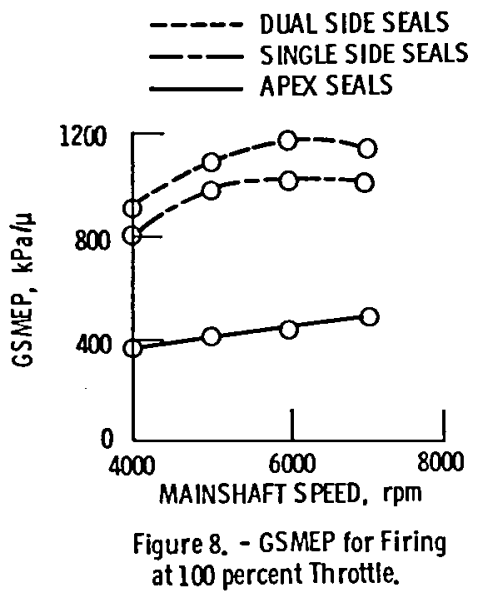

To examine this concept, a high pressure bomb and furnace were constructed to study the combustion of $n$-dodecane and $n$-heptane, the major components of diesel fuel. This study was conducted at supercritical conditions. The furnace and bomb were fitted with windows for optical access and the appropriate pressure transducers and thermocouples to monitor the experiment. Fuel was supplied to the preheated bomb by a modified Roosa-Master fuel injector suitable for operation at high temperatures. This apparatus is capable of maintaining pressures of $21 \mathrm{~atm}$ at $800^{\circ} \mathrm{K}$ within the bomb, the injected fuel being at the same temperature.

Concurrently, the Berkeley group developed a technique for the determination of pure hydrocarbon properties below, at, and above the critical point. Data obtained to date are shown in Figure 9. Examination of the data shows a substantial reduction in ignition delay with temperature. As most of the ignition delays of interest in modern diesel engines are less than $2 \mathrm{~ms}$ it is important to make ignition studies under ambient conditions that will promote ignition delays below this time interval. This experiment has gradually reached this goal, and investigations presently underway will yield more detailed results within this regime.

Numerical study of flowfields in a motored four-stroke piston-cylinder configuration. An indispensable part of understanding combustion in an engine is understanding the airflow in the combustion chamber. As a first step toward being able to predict the velocity fields and turbulence levels in a multivalve engine where three-dimensional effects are very important, we have chosen to model an axisymetric pistoncylinder configuration. The two-dimensional model which has been under development on grant $^{20}$ has many of the essential features of three-dimensional models. Measurements can be made for model validation in an axisymmetric piston-cylinder configuration where the dominant features of the flow are two-dimensional.

Results of this simulation have been published 21 and are now briefly described.

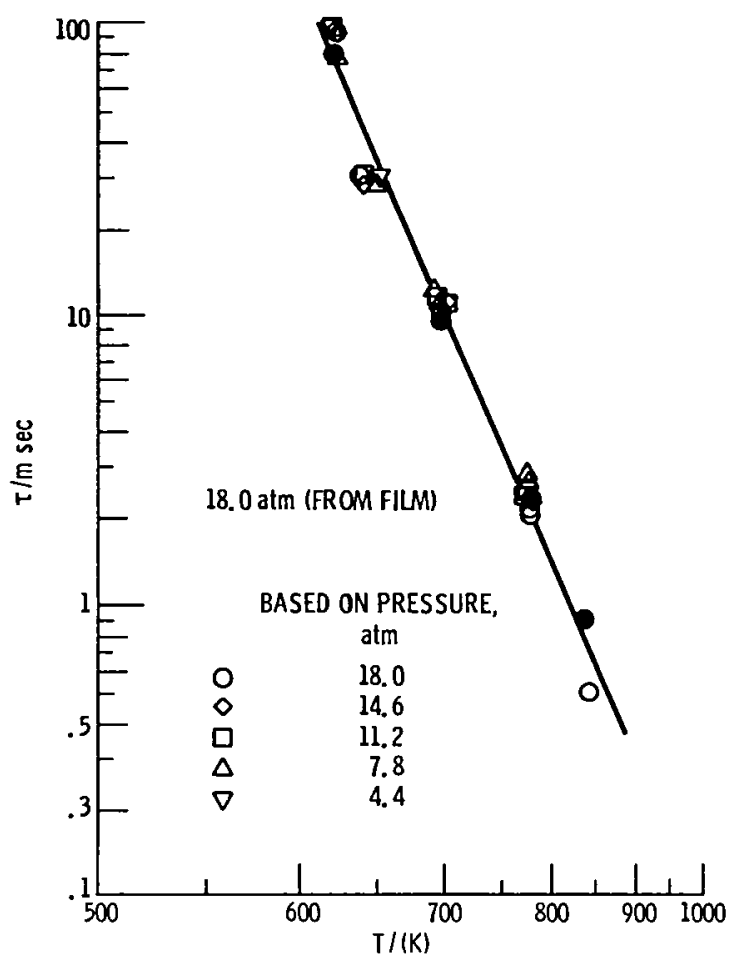

Figure 9. - Variation in ignition delay with temperature and pressure.

The effects of the compression ratio, engine speed, bore-to-stroke ratio and air intake flow angle on the turbulent flow field within an axisymmetric piston-cylinder configuration have been investigated numerically by means of a finite-difference procedure which solves the conservation equations of mass, momentum and energy. Turbulence has been modeled by means of a two-equation model for the turbulent kinetic energy and the dissipation rate of turbulent kinetic energy. The motion of the piston has been accounted for by introducing a mapping which transforms the moving boundary problem associated with the piston motion into a fixed boundary problem. The valve motion within the cylinder has been analyzed by defining a fixed grid in which the valve can move in such a way that its profile corresponds to that of an intake/exhaust valve in a four-stroke engine. The numerical results show that the flow field is sensitive to the engine geometry and very sensitive to the valve seat angle. Higher compression ratios produce higher rms velocity values within the cylinder. For an air intake 
flow angle of $45^{\circ}$ (see Figure 10 ), the flow field within the cylinder shows three elongated vortices formed during intake which persist into the compression stroke. These vortices break-up and merge in the compression stroke. Other vortical structures are formed and persist into the expansion stroke. For an air intake angle of $0^{0}$, (see Figure 10 ), the flow field consists of two vortices which disappear by the end of the compression stroke. The effects of the boreto-stroke ratio on the flow field indicate that for the long strokes, high levels of turbulent kinetic energy are present within the cylinder. These turbulence levels are very sensitive to the geometry of the system of interest. $0^{\circ}$ INTAKE AIR ANGLE

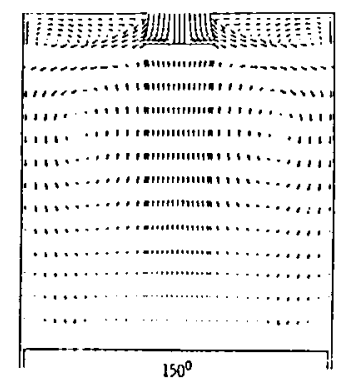

$45^{\circ}$ INTAKE AIR ANGLE

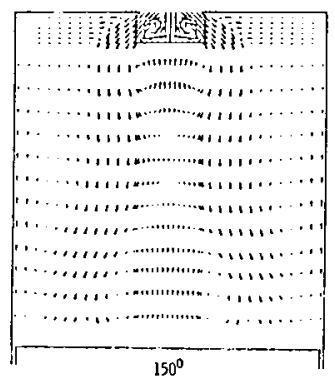

Figure 10. - Variation of flowfield $150^{\circ}$ ATDC with a change in intake air direction. (Bore $/$ stroke $=1, r \mathrm{pm}=1000$, comp. ratio $=7.0)$.

The numerical results also indicate that the velocity field and turbulent kinetic energy field prior to TDC are very sensitive to the air intake flow angle and the bore-to-stroke ratio. These parameters play an important role in determining the engine combustion efficiency, heat losses and pollutant formation.

Thermodynamic modeling of rotary combustion engines. The stratified-charge rotary engine has the potential to be a competitive choice to be used as a future power plant for light aircraft. 22 To gain a better insight into the operation of this engine, a thermodynamic model is being developed under grant 23 to study and predict engine performance, emissions, and fuel economy.

An exjsting piston engine simulation was modified 24 to accomodate the rotary engine geometry for preliminary performance and sizing calculations. This simulation employs a homogeneous change spark-ignition combustion model which includes a prespecified fuel rate burning model. In addition to change in geometry, a crevice volume and leakage model were added to the simulation. Motoring RCE data was used to calibrate the model. A parametric study for light loads showed that gas leakage is the predominant effect on engine performance. At light loads, crevice volumes and heat transfer had little effect; however, these are expected to become more important at high speeds and loads.

Recent work on this thermodynamic model has been focused on the development of a stratifiedcharge combustion model. Heat release will be calculated from pressure-crank angle data. Thermodynamic property analysis, heat transfer, crevice and leakage submodels are also included in the formulation of this model.

Detailed combustion chamber pressure and performance data is now being obtained ${ }^{25}$ for the stratified-charge rotary engines of interest. When this data is analyzed using this model, a better understanding of the processes occurring within the RCE will be obtained.

Multidimensional rotary combustion engine codes. A numerical study of the fluid flow, heat transfer, and combustion processes inside the combustion chambers of a direct-injection, stratified-charge rotary engine has been undertaken.

Under NASA grant, 26 efforts are presently underway at the University of Florida to develop two numerical codes for studying the fluid mechanics, the heat transfer, and the combustion that occurs within the rotary engine combustion chambers. One of the numerical codes (2-D code) is for studying an idealized two-dimensional rotary engine. The other numerical code (3-0 code) is for studying a more realistic threedimensional rotary engine. Progress made in the development of these two codes is described below.

The two-dimensional code is based on the numerical solutions of the ensemble averaged conservation equations of mass, species, radial momentum, azimuthal momentum, and thermal energy. The ensemble averaged conservation equations were closed by the K-E model of turbulence, which was modified to account for some of the effects of streamline curvature and compressibility.

To obtain numerical solutions to the conservation equations described above, the continuous domain inside one of the combustion chambers of the rotary engine was represented by a grid system. The grid system was generated by an algebraic grid generation technique. It moves and deforms with the combustion chamber as the combustion chamber moves with the rotor. The conservation equations were first transformed to a moving coordinate system corresponding to the motion of the grid system, and were then expressed in finite-difference form.

Some of the preliminary outputs of the twodimensional code are shown in Figure 11. At the present time, various boundary conditions for the intake, exhaust, and fuel injection ports are still being tested for accuracy and numerical stability. With the intake, exhaust, and fuel injection ports closed, numerical experiments conducted so far have indicated that the numerical solutions generated by the two-dimensional code were stable and physically reasonable if the Courant number was kept less than 60 .

The three-dimensional code is based on the two-dimensional code with the following modifications:

1. The ensemble averaged axial momentum equation is added to the conservation equations employed in the twodimensional code. 
2. All of the conservation equations described previously are generalized to include three spatial coordinates.

3. The ensemble averaged conservation equations for the three-dimensional code are closed by an algebraic stress equation model of turbulence instead of the $\mathrm{K}-\mathrm{E}$ model of turbulence.

The development of the three-dimensional code is still in the programing stage.

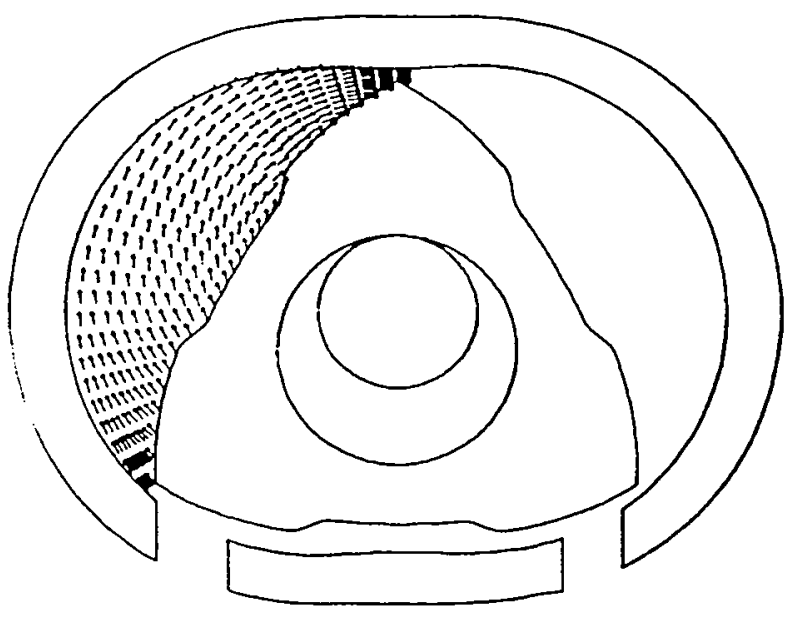

Figure 11. - RCE multidimensional model output.

\section{Summary}

The goal of developing a highly efficient, light weight aircraft engine will only be achieved by a concerted program composed of practical engine studies and experiments, within which the results of basic research work can be applied. As part of that program, the Intermittent Combustion Engine Branch at NASA Lewis Research Center has underway research work whose objective is to understand the internal processes which occur in rotary and piston engines. This work involves both numerical simulations and detailed experimental studies. The emphasis of this basic research effort is to gain a fundamental understanding of the important processes affecting combustion in piston and rotary engines.

\section{References}

1. Poulos, S. G. and Heywood, J. B., "The Effect of Chamber Geometry on Spark-Ignition Engine Combustion," SAE Paper 830334, 1983.

2. Rice, W. J., "Development of an Instrument for Real-Time Computation of Indicated Mean Effective Pressure," NASA TP 2238, Jan. 1984.

3. Green, R. M, Smith, J. R. and Medina, S. C., "Optical Measurements of Hydrocarbons Emitted from a Simulated Crevice volume in an Engine," SAE Paper 840378, Feb. 1984.
4. Witze, P. 0., Martin, J. K. and Borgnakke, C., "Fluid Motion During Flame Propagation in a Spark-Ignition Engine," SAE Paper 840377, Feb. 1984.

5. "Improving Internal Combustion Engines," Sandia Technology, Vol. 7, No. 1, Feb.'198, pp 2-11.

6. Grosser, M., Diesel, The Man and the Engine, Athen ium, 1978.

7. Miller, C. D., "A Study by High Speed Photography of Combustion and Knock in a Spark Ignition Engine," NACA Report 727, 1942.

8. Cordin, 2230 South 3270 West, Salt Lake City, Utah, USA 84119.

9. Miller, C. D., personal communication, February 1984 .

10. Richman, R. M. and Reynolds, W. C., "The Development of a Transparent $C y l$ inder Engine for Piston Engine Fluid Mechanics Research," SAE Paper 840379, Feb. 1984.

11. Shih, T. I-P., Smith, G. E. and Springer, G. S., "Numerical Simulation of the Flow and Fuel-Air Mixing in an Axisymmetric PistonCylinder Arrangement," NASA TM 83011, Oct. 1982.

12. Gosman, A. D., Tsui, Y. Y. and Watkins, A. P., "Calculation of Three-Dimensional Air Motion in Model Engines," SAE Paper 840229, Feb. 1984 .

13. Arcoumanis C., Bicen, A. F. and Whitelaw, J. H., "Effect of Parameters on the Flow Characteristics in a Four-Stroke Model Engine," SAE Paper 820750, June 1982.

14. Ekchian, A. and Hoult, D. P., "Flow Visualization Study of the Intake Process of an Internal Combustion Engine," SAE Paper $790095,1979$.

15. Schock, H. J., Regan, C. A., Rice, W. J. and Chlebecek, R. A., "Multi-component Velocity Measurements in a Piston-Cylinder Configuration Using Laser Velocimetry," NASA TM 83534, Dec. 1983.

16. Sathyakumur, R., "Differential Doppler Techniques for On-Axis Backscatter Measurements," U.S. Patent No. 4263002, 1981.

17. Schock, H. J., Case, S. and Konicek, L., "Window Aberration Correction in Laser Velocimetry Using Multifaceted Holographic Optical Elements," Applied Optics, Vol. 23, No. 5, Mar. 1, 1984, pp 752-56.

18. Knoll, J., Vilmann, C. R., Schock, H. J. and Stumpf, R. P., "A Dynamic Analys is of Rotary Combustion Engine Seals," SAE Paper 840035, Feb. 1984 
19. Oppenheim, A. K., Principal Investigator, "Study of Jet Ignition Using Liquid Fuels," NASA Grant NAG3-137, University of California - Berkeley, Berkeley, California, Dec. 1980 - Dec. 1983.

20. Ramos, J. I., Principal Investigator, "A Numerical Study of the Flow Field, Flame Propagation and Emissions in a Two-Stroke Diesel Engine," NASA Grant NAG3-21, CarnegieMellon University, Pittsburgh, PA, oct. 1983 - Oct. 1984.

21. Schock, H. J., Sosoka, D. J. and Ramos, J. I., "Numerical Studies of the Formation and Destruction of Vortices in a Motored FourStroke Piston-Cylinder Configuration, "AIAA Paper 83-0497, Jan. 1983.

22. Huggins, G. L. and Ellis, D. R., "Advanced General Aviation Comparative Engine/Airframe Integration Study," Cessna Aircraft Company, Wichita, Kansas, Cessna AD-127, (NASA (R-165564), Sept. 1981.
23. Heywood, J. B., Principal Investigator, "Generalized Internal Combustion Engine Cycle Simulations: Direct-Injection Stratified-Charge Rotary Engines for Aircraft Applications," NASA Grant NAG3-82, Massachusetts Institute of Technology, Cambridge, Massachusetts, July 1983 - Feb. 1984.

24. Norman, J. T., "A Performance Model of a Spark Ignition Wankel Engine: Including the Effects of Crevice Volumes, Gas Leakage, and Heat Transfer," M.S. Thesis, Massachusetts Institute of Technology, Cambridge, Massachusetts, June 1983.

25. Experimental Studies Underway at Lewis Research Center, Cleveland, Ohio, 1984.

26. Shih, T. I-P., Principal Investigator, "A Numerical Study of the Fluid Flow, Heat Transfer and Combustion Processes Inside the Combustion Chambers of a Direct-Injection Stratified-Charge Rotary Engine," NASA Grant NAG3-363, University of Florida, Gainesville, Florida, Jan. 1983 - Dec. 1983. 


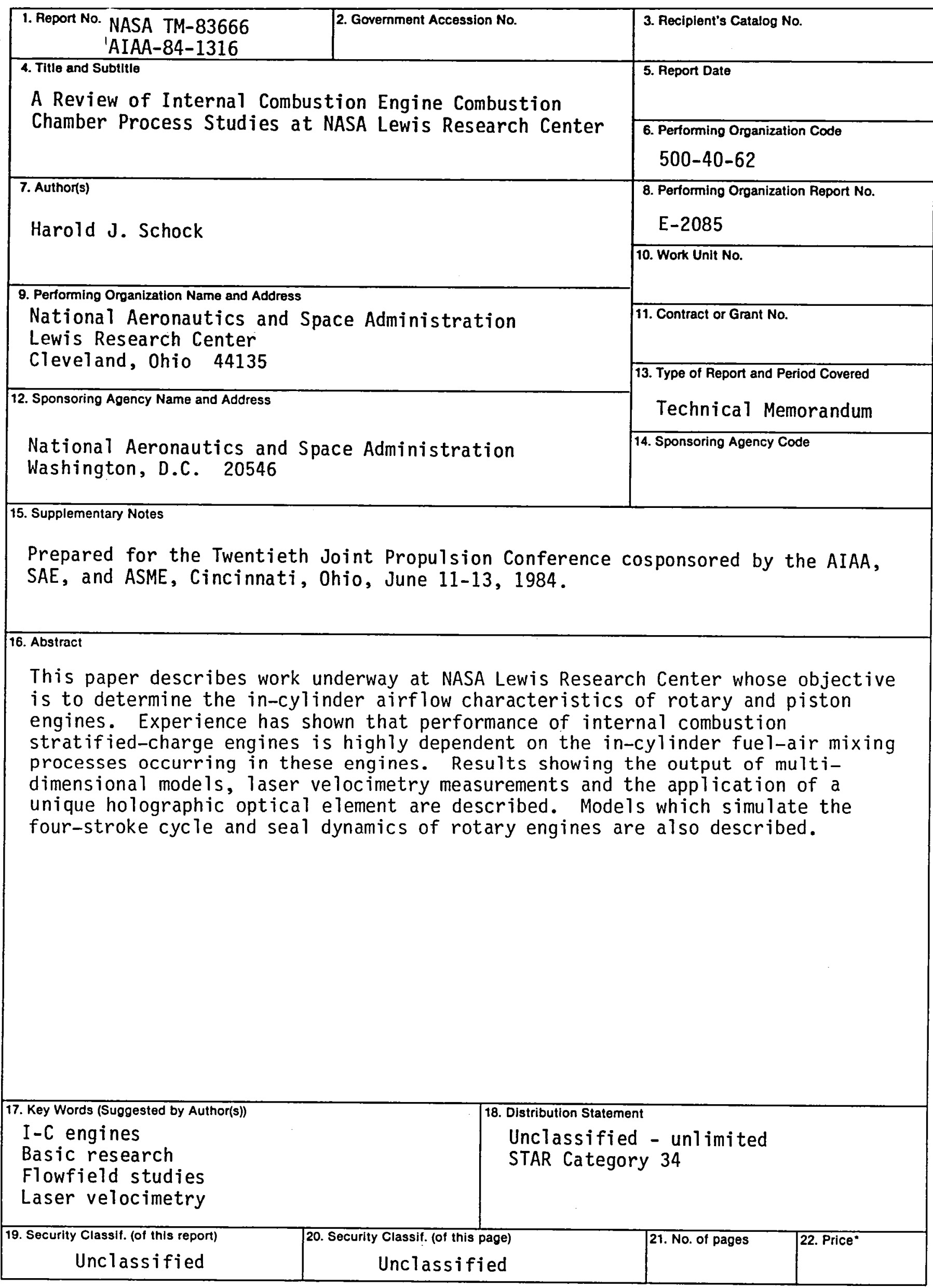

"For sale by the National Technical Information Service, Springfield, Virginia 22161 

National Aeronautics and Space Administration BOOK

Washington, D.C.

20546

Official Business

Penalty for Private Use. $\$ 300$

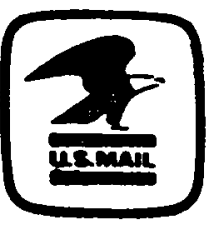

Portage and Fees Paid Netional Aeronoutics and: Spuce Administration NASA-45i 